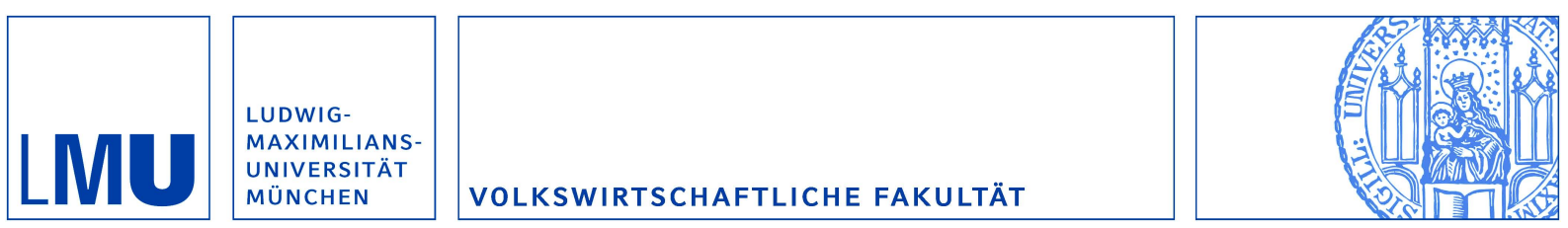

Hendel, Ulrich:

The Influence of Altruistic Preferences on the Race to the Bottom of Welfare States

Munich Discussion Paper No. 2012-21

Department of Economics

University of Munich

Volkswirtschaftliche Fakultät

Ludwig-Maximilians-Universität München

Online at https://doi.org/10.5282/ubm/epub. 13999 


\title{
The Influence of Altruistic Preferences on the Race to the Bottom of Welfare States*
}

\author{
Ulrich Hendel ${ }^{\dagger}$
}

\begin{abstract}
Common tax competition models suggest that welfare states will undercut each other's tax rate to attract taxpayers and keep welfare recipients at bay. This will lead to a zero-taxation outcome in the absence of migration costs or other barriers to migration. This paper develops a twocountry framework with mobile altruistic taxpayers and immobile welfare recipients. It shows that under the assumption of taxpayers motivated by warm glow altruism, tax competition leads to unique pure strategy Nash equilibria in taxation which are different from zero given sufficiently strong altruistic preferences. If countries are asymmetric with respect to the number of welfare recipients, pure altruism and inequity aversion preferences support additional unique pure strategy Nash equilibria in which the country with the fewer poor attracts more taxpayers and sets higher taxes. This implies that rich countries may benefit from tax competition.
\end{abstract}

JEL Classification: H73, D64, H20

Keywords: tax competition; welfare state; altruism

*I am very grateful for helpful comments and suggestions by Matz Dahlberg, Andreas Haufler, Peterhans Hendel, Sebastian Jauch, Panu Poutvaara, Klaus Schmidt, Christian Traxler and Silke Übelmesser. I am also grateful to the participants of the Public Economics seminar at the LMU for the productive discussion. Financial support from the Deutsche Forschungsgemeinschaft through GRK 801 is gratefully acknowledged.

${ }^{\dagger}$ Munich Graduate School of Economics, Ludwig-Maximilians-Universität Munich, Kaulbachstr. 45, D-80539 Munich. Phone: +49 1715328457.

Email: Ulrich.Hendel@lrz.uni-muenchen.de 


\section{Introduction}

Most taxation, be it income tax, property tax, compulsory health or unemployment insurance, constitutes a form of wealth transfer from taxpayers in the higher income brackets to those with low or no income. Therefore, the tax competition literature argues that regions and countries compete for a mobile tax base consisting of redistribution-averse taxpayers which leads to a destructive Race to the Bottom in taxes. This in turn makes the provision of tax-financed public goods and welfare transfers all but impossible in the worst case. ${ }^{1}$ However, the empirical evidence for this phenomenon is rather mixed. ${ }^{2}$

In contrast to what the Race to the Bottom theory suggests, some countries with high tax rates seem to have a high appeal for taxpaying migrants, as can be seen from European migration patterns of highly qualified personnel (see Figure 1). Norway with a tax wedge of $43 \%$, Sweden with $50.9 \%$ and Belgium with $60.5 \%$ (OECD, 2010) for high-earning singles, for example, are able to sustain tax rates above the OECD average of $41.1 \%$ and are still attractive for European migrants. ${ }^{3}$ One could argue that in the case of Norway low unemployment rates and high net incomes are the dominant reasons for the net influx of 40,000 migrants in 2009 (Statistics Norway, 2009). But Sweden and particularly Belgium did not display low levels of unemployment and high net incomes between 2005 and 2009 as can be seen from Table 1. Furthermore, while Denmark and the Netherlands (which are countries characterized by high net wages and low unemployment in European comparison) lost highly qualified taxpayers between 2005 and 2009, Germany, a country with high taxes and high unemployment in European comparison had a net migration of about zero. A common feature of Germany, Sweden and Belgium is the high publicly mandated social expenditure as a share of GDP. Thus, high taxes in combination with generous welfare transfers do not seem to be a deterrence for many migrants. This is at odds with the notion that taxpayers aim to pay as little taxes as possible, maximize disposable income and migrate accordingly.

In this paper, I will show that a full Race to the Bottom in taxes does

\footnotetext{
${ }^{1}$ Of course, tax competition can also have beneficial effects such as fiscal restraint and efficiency gains. For an overview, see Wilson (1999).

${ }^{2}$ Among the proponents of a Race to the Bottom are Brueckner (2000), Dahlberg and Edmark (2008) and Kleven et al. (2010). Other motivations for migration and tax competition prevail in research by Volden (2002), Bakija and Slemrod (2004) and van Dalen and Henkens (2007).

${ }^{3}$ The OECD defines the tax wedge as the ratio between income tax, employer and employee social contributions minus cash transfers to labour costs. The tax wedge does not include additional compulsory contributions to privately managed pension funds or insurances.
} 
not need to occur under the assumptions of immobile poor welfare recipients and perfectly mobile altruistic taxpayers who cannot decide on their income tax levels. I will further distinguish between three types of altruism which are discussed in detail in section 2: pure altruism as formulated by Weichenrieder and Busch (2007), inequity aversion as proposed by Fehr and Schmidt (1999), and warm glow as put forward by Andreoni (1990). Both inequity aversion and warm glow have so far not been used to motivate taxation.

If warm glow preferences are assumed and altruistic sentiments are sufficiently strong, an asymptotically stable unique pure strategy NE exists in which taxation occurs. Furthermore, if countries are asymmetric with respect to the number of poor, it is shown that there are stable pure strategy NE with pure altruism and inequity aversion preferences. The model also suggests that rich countries have an advantage in the competition for taxpayers. The aim of this paper is to highlight a factor other than migration costs, namely altruistic preferences, which may help to explain why high tax, high welfare benefit countries such as Germany do not suffer from a significant flight of their taxpayers.

The first economic models to deal with the tax erosion issue were mainly focused on tax competition within federations. ${ }^{4}$ European integration has then sparked research on the reaction of taxes and welfare states to a trans-national increase in mobility and free labour market access. ${ }^{5}$ For a survey of the effects of factor mobility on redistribution, see Cremer and Pestieau (2004).

Directly related to this paper is the contribution by Weichenrieder and Busch (2007). They present a framework in which zero taxation is the outcome in a federation with perfectly mobile, non-altruistic taxpayers and immobile poor who decide on the level of taxation. The same result is achieved under the assumption of immobile homogenous taxpayers with pure altruism preferences who can also decide on the tax rates, and perfectly mobile poor. Altruism is modeled such that the amount of money transferred to each individual poor person enters the utility function of the taxpayers. Imposing further restrictions on the relative numbers of poor and rich citizens, the authors predict a full Race to the Bottom in taxes in the absence of a mechanism such as "delayed integration"

\footnotetext{
${ }^{4}$ The analysis was centered on externalities from taxation and migration, possible tax and transfer mechanisms to account for these externalities and general equilibrium effects from tax competition. See, for instance, Pauly (1973), Wildasin (1991), Crane (1992) and Mansoorian and Myers (1993). In a world without migration costs, the outcome in these models is generally zero taxation.

${ }^{5}$ See, for instance, Cremer and Pestieau (1998), Razin et al. (2002), Sinn (2003) and Egger and Radulescu (2009).
} 
under both mobility assumptions. ${ }^{6}$ Weichenrieder and Busch (2007) do not consider the case in which taxpayers are mobile, altruistic and heterogeneous with respect to the strength of their altruistic sentiment and welfare recipients are immobile. But this setting is interesting as, given the formulation of altruistic preferences, the migration decision of the rich now not only depends on the number of poor, but also on the number of other taxpayers in their jurisdiction. The altered mobility assumptions are also in line with real world observations, as explained in section 3.1.

I show that this variation of assumptions is sufficient to prevent a full Race to the Bottom with a warm glow formulation of altruism, even in the absence of the "delayed integration" mechanism. The public good character of redistribution introduces enough "stickiness" into migration decisions to allow for non-zero taxation. Furthermore, introducing asymmetry with respect to the number of immobile poor allows for stable $\mathrm{NE}$ with inequity aversion and pure altruism preferences. Here, the heterogeneity of taxpayers' redistributive preferences is also crucial.

Several arguments other than altruism have been put forth in the literature to explain why a redistributive welfare state can survive in the presence of taxpayer mobility.

First, welfare transfers act as an insurance against the sudden loss of one's earning ability through, say, unemployment, and insurance through redistribution can cover risks for which no private insurance market exists (Sinn, 1996). But wealthy taxpayers with safe jobs should prefer not to insure at all or to insure themselves privately to keep out the "bad risks" as they end up being net contributors in public welfare and insurance schemes.

Second, migration costs have been put forward as a reason for the possibility of taxation: Citizens can be taxed simply because leaving the jurisdiction is more costly (in monetary or psychological terms) for them than paying their taxes (Mansoorian and Myers, 1993). But with increasingly multilingual populations, fast and cheap means of transport and advanced communication via the internet, these costs should be falling, especially for young and well educated professionals which constitute the group most likely to migrate. ${ }^{7}$

\footnotetext{
6"Delayed integration" means that a taxpayer has to pay the tax rate of the country he was living in at the start of the period, even if he migrates during the period. Tax rates are announced at the beginning of a period before migration can take place. In a tax competition game between two countries with finite number of periods, this mechanism is sufficient to prevent an outcome of zero taxation.

${ }^{7}$ E.g., Thompson (2009) finds a high willingness to migrate particularly in this group.
} 
Third, political scientists have argued that tax competition might not take place due to domestic and transnational political constraints (Basinger and Hallerberg, 2004; Gilardi and Wasserfallen, 2010): On the one hand, the majority of the electorate could oppose lowering tax rates levied on the rich due to ideological reasons even if, for instance through a Laffer curve effect, this were to increase tax revenues. On the other hand, governments might adhere to informal, non-enforceable agreements with other countries and do not deviate unilaterally, so the Prisoner's Dilemma of the Race to the Bottom is solved by simply agreeing to play the mutually beneficial strategy. These constraints violate rationality assumptions commonly made in economics and are therefore debatable.

The next section presents different concepts of altruism which will be incorporated into a tax competition model with warm glow in section 3 and with pure altruism and inequity aversion in section 4 . Section 5 concludes.

\section{Concepts of altruism}

The idea that humans are not guided purely by economic considerations, but by a divinely commanded, innate or acquired concern for their fellow man has been around for millennia. ${ }^{8}$ However, incorporating this notion into an economic model requires modifications to the concept of the self-interested, coldly calculating homo oeconomicus. This section presents three different approaches to the idea of altruism.

A first concept is pure altruism. For instance, the formulations of altruism in Wildasin (1991) and Weichenrieder and Busch (2007) are in line with this notion. One could imagine that taxpayers receive utility from the tax-financed welfare benefit an individual poor person in their jurisdiction receives. This could be because they are genuinely "good" people who feel empathy for the lot of others. ${ }^{9}$ Or they could just as well be motivated by purely egoistic reasons: Having beggars off the streets, reducing poverty-related crime or, generally speaking, "keeping the masses quiet" are motivations that can be captured by a

\footnotetext{
${ }^{8}$ Charity is demanded in both the Old and New Testament and the Qu'ran. The causes and effects of charity are an important issue in Thomas Aquinas' "Summa Theologiae" (Ney, 2006), and Immanuel Kant (1785) deduces the duty of charity from his notion of the categorical imperative.

${ }^{9}$ In Germany, wealthy taxpayers like Dietmar Hopp (one of the founders of SAP) and a club of 50 millionaires have demanded higher income taxation instead of social welfare cuts to overcome the current dire fiscal situation (Hamburger Abendblatt, 2010; ZDFinfokanal, 2010).
} 
preference for income redistribution. Furthermore, it could be the case that the productivity and/or income of a rich taxpayer depends on the human capital of the poor as he might need educated workers for his factories, as assistants, etc. Income redistribution to pay for the poor's education is therefore rational for taxpayers even though they do not care about the living conditions of the poor per se. ${ }^{10}$

But utility from pure altruism does not depend on one's own contribution in large societies and therefore suffers from free-riding issues related to public goods. ${ }^{11}$ The individual contribution has a minimal effect on the total provision of welfare benefits, and thus each taxpayer would state zero as his own preferred tax rate. This implication of the notion of pure altruism has already been noted, albeit not in its negative implications, by the German moral philosopher J.G. Fichte in the late 18th and early 19th century. Fichte stated that a good person wants good acts to take place and does not care by whom they are performed (no year). There is also experimental evidence for this shortcoming of a purely altruistic motivation, e.g. by Palfrey and Prisbrey (1997) who fail to find purely altruistic preferences in a voluntary contributions experiment.

A second concept is inequity aversion, which has come up in recent research as a possible driving force behind income redistribution. Here, it is not concern for the income of others, but worries about the difference between one's own income and that of others which leads to voluntary giving. Fehr and Schmidt (1999), as well as Bolton and Ockenfels (2000) find that equity preference can explain a wide range of experimental outcomes, ranging from completely selfish behavior to full cooperation, in public good and dictator games. In addition to fairness considerations as expressed in Bolton and Ockenfels' idea of "equity and reciprocity", the same basically egoistic motivations for an aversion to inequity as in the pure altruism case apply.

Finally, a third approach to motivate altruistic behavior is warm glow altruism which has been put forward by Andreoni (1990) and tested, amongst others, by Palfrey and Prisbrey (1997) and Crumpler and Grossman (2008). According to the warm glow theory, the act of giving generates utility for an individual as he or she experiences a good feeling from being generous. Neither the utility of the donation recipient nor the total provision of a good financed by donations matters, only the individual contribution. The opposite effect, a "cold chill", an-

\footnotetext{
${ }^{10}$ This idea is also found in Alesina and Giuliano (2009) and earlier work.

${ }^{11}$ For a discussion of group size effects on public good provision see, for instance, Isaac and Walker (1988).
} 
alytically works in the same way with an inverted sign and captures the pangs of conscience generated by not adhering to a social norm, to the direct request of a fund raiser or similar external demands for charity.

One could argue that warm glow can only be applied to truly voluntary giving, like donations to charities, but there are reasons why it might also be reasonable to consider warm glow preferences in connection with taxation. A mobile individual does not have to take the tax rate of a country as given but can migrate to another country, and hereby choose his or her own preferred contribution to the welfare state. Therefore, in a setting with competing countries, taxes become, at least to some extent, a choice variable for individuals. Civic duty, resulting from an upbringing in an environment in which taxation and redistribution is the acknowledged social norm, might also induce individuals to feel a warm glow (or at least avoid a cold chill) by paying their taxes as they are fulfilling their perceived obligations towards society. In this respect, warm glow can be seen as being related to the notion of "tax morale". ${ }^{12}$

Finally, as Schlicht (1998) argues with his self-attribution theory, the mere fact of doing something might lead one to like it even if another salient reason, such as compulsion, is at hand. Hence, taxpayers might either try to fulfill an obligation by paying taxes or satisfy an "acquired taste" for redistribution.

It is clear that altruism, if it is only selfishness in disguise, should extend to the residents of a country the altruistic taxpayer lives in, not just to poor of the same nationality. But even if altruism stems from unselfish motives, it is reasonable to assume that altruistic feelings should be directed first and foremost towards the poor which are visible, close-by and receive local, regional or national news coverage. Thus, in the remainder of the paper it is assumed that mobile taxpayers have altruistic sentiments towards the poor in the jurisdiction they live in.

Having established the applicability of theories of altruism on taxation, I will now turn to a model incorporating altruistic preferences in a tax competition framework.

\footnotetext{
12"Tax morale" can be defined as the "intrinsic motivation to pay taxes arising from the moral obligation to pay taxes as a contribution to society" (Cummings et al., 2009). Particularly in Germany, a tax morale effect could be at work as minimizing the personal tax load through the myriads of deductions laid down in the German tax code can be considered the social norm, so paying the "normal" amount already amounts to something akin to voluntary giving (c.f. Doerrenberg et al., 2012)
} 


\section{A model of tax competition with warm glow preferences}

\subsection{General framework}

In this section, I will present a model of two countries competing for mobile altruistic taxpayers. In the related literature, varying mobility assumptions for "rich" and "poor" persons have been used. However, migrants are often restricted from entering a country's social welfare system without first contributing to it. ${ }^{13}$ Furthermore, affluent and well-educated persons usually have more options when considering employment abroad. Finally, Ette and Sauer (2010) show that the share of highly qualified personnel emigrating from Germany is disproportionately high. I therefore consider the case of mobile "rich" and immobile "poor" to be the most interesting one.

For altruistic taxpayers, income transfers can be seen as a local public good (c.f. Pauly, 1973 and Orr, 1976), so they go "shopping" (c.f. Tiebout, 1956) for their preferred rate of taxation and redistribution. It is important to notice that altruism can call for very peculiar public goods: With warm glow altruism, only the own contribution creates utility, while public goods generally create utility through total contributions. Under the assumption of inequity aversion, the own contribution via its effect on disposable income also affects the utility from redistribution. Only redistribution motivated by pure altruism is a classic pure public good.

There are two countries, $i$ and $j$, which maximize the welfare transfer they can offer to their local, immobile poor by maximizing tax revenue. The number of welfare recipients is given by $n_{i}$ in country $i$ and $n_{j}$ in country $j$. Governments are interested in revenue maximization for redistributive purposes as their reelection depends on the welfare recipients: If the decisive voter in a country is a poor person, the government will cater for his redistribution preferences if it is interested in staying in office. The decisive role of a poor voter is ensured within the model's framework by assuming that the number of immobile poor within each country is greater than the total number of mobile taxpayers. Even if all taxpayers were to migrate to one country they would still be outnumbered and outvoted by the poor, which is an assumption also made in Weichenrieder

\footnotetext{
${ }^{13}$ In Germany, § 23 para. 3 Sozialgesetzbuch (Social Security Code) XII states that foreigners entering the country for the sole purpose of obtaining social security benefits are excluded from said benefits.
} 
and Busch (2007). Given the typical empirical result that the median of the income distribution is lower than its mean, and that the median voter is thus a beneficiary of a redistributive welfare system, this assumption seems justifiable (c.f. Meltzer and Richard, 1981). The transfer constitutes the only income for welfare recipients. By taking into account the migration decisions of the taxpayers which are determined by their utility functions, governments implicitly also have to consider the welfare of the rich.

This model setup implies that in autarky, i.e. if taxpayers were not mobile, countries would try to fully expropriate taxpayers. To prevent full expropriation, one could assume that the possibility of taxation is restricted by bureaucratic inefficiencies so that the highest possible tax rate is smaller than the exogenous income (Weichenrieder and Busch, 2007). Countries will thus only suffer tax revenue reductions with mobile taxpayers if tax competition drives equilibrium tax rates below those possible in autarky. ${ }^{14}$

Countries $i$ and $j$ collect a lump-sum tax $b_{i}, b_{j}$ with $0 \leq b_{i}, b_{j} \leq x$ from a continuum $K$ with mass 1 of costlessly mobile taxpayers earning an exogenously given income $x>0$ who incorporate some form of altruism, to be specified later, in their utility functions. As stated above, to make the decisive voter a welfare recipient it is assumed that $n_{i}, n_{j}>1$. Taxpayers are heterogeneous with respect to to the strength of their altruistic motivation. It is assumed that each country initially hosts one half of the mass of taxpayers, and that taxpayers do not have a home country preference, i.e. they do not intrinsically prefer living in one country over the other. Given the strength of his or her altruistic feeling, the tax rate and (in the case of inequity aversion and pure altruism) the number of immobile poor in each country, a taxpayer decides on whether to stay in his home country or migrate. Furthermore, taxpayers are unable to coordinate their migration decisions even if it were beneficial for them to all settle in the same country, and they take each others migration decision as given.

Taxpayer $k \epsilon K$ is assumed to have the following quasi-linear utility function

\footnotetext{
${ }^{14}$ An upper bound on redistribution could also be introduced by shedding the assumption that welfare recipients always outnumber taxpayers. But this would pose two problems. First, taxpayers would all want to settle within the same country to maximize their vote share. If the migration decision of a taxpayer depends on that of other taxpayers, a stable pure strategy NE may no longer exist as will turn out to be the case with pure altruism and inequity aversion preferences. Second, it would become necessary to calculate the decisive median voter. If he were a taxpayer, his location on the $\alpha$ - continuum would depend on the number of poor within the jurisdiction as all welfare recipients would prefer full expropriation. In turn, even with warm glow preferences the amount of redistribution would become dependent on the number of poor.
} 
if he settles in country $i:{ }^{15}$

$$
U_{k, i}=V\left(x-b_{i}\right)+\alpha_{k} W\left(b_{i}\right)
$$

$V$ is a concave function of the taxpayer's disposable income with $V(0)=$ $0, \frac{\partial V}{\partial x}(0)=\infty, \frac{\partial V}{\partial x}>0, \frac{\partial^{2} V}{\partial x^{2}}<0 . \quad W$ is a linear function and can be specified to account for different types of altruism (see Table 2). $\alpha_{k}$ is the strength of $k$ 's altruistic motivation, with $0<\alpha_{k} \leq l$. The assumption of $0<\alpha_{k} \leq l<\infty$ is needed to ensure the stability of the NE. ${ }^{16}$ In the following sections, it is assumed that $\alpha_{k}$ is drawn from a truncated normal distribution between 0 and $l$ with mean $=$ median $\mu, 0<\mu<l$, and standard deviation $\sigma>0 .{ }^{17}$ Note that taxpayers are costlessly mobile, which leads to a zero taxation outcome in the absence of altruism. Taxpayers also only care about welfare transfers in the country they settle in. ${ }^{18}$

Given the tax rates $b_{i}$ and $b_{j}$, it can be determined where each individual taxpayer will settle by calculating a cutoff level $\alpha^{*}$ which corresponds to a taxpayer's $\alpha$ who is just indifferent as to which country he lives in. This is done by setting the utility a taxpayer would gain in each country (given by (1)) equal and solving for $\alpha^{*}$ :

$$
\begin{gathered}
V\left(x-b_{i}\right)+\alpha^{*} W\left(b_{i}\right)=V\left(x-b_{j}\right)+\alpha^{*} W\left(b_{j}\right) \\
\Rightarrow \alpha^{*}=\frac{V\left(x-b_{j}\right)-V\left(x-b_{i}\right)}{W\left(b_{i}\right)-W\left(b_{j}\right)}
\end{gathered}
$$

Assuming the same number of poor in each country, a taxpayer $k$ with $\alpha_{k}>\alpha^{*}$

\footnotetext{
${ }^{15}$ As this paper neither examines distributional questions nor principal-agent problems, the critique of the quasi-linearity assumption in public finance and political economy models as put forward in the introduction of Dixit et al. (1997) does not apply. As Boadway et al. (2002) notice, the quasi-linearity assumption is of course questionable but commonly used. In the context of this paper, it makes the most sense to attribute the concave part to disposable income, as this ensures that at least for small incomes disposable income is preferred to altruistic redistribution.

${ }^{16}$ Including the zero bound makes it possible for a country to always attract marginally more taxpayers by marginally lowering the tax rate. If $\alpha$ were infinite, a country could always attract marginally more taxpayers by setting a higher tax rate. An unbounded distribution of altruistic preferences is also an unrealistic assumption.

${ }^{17}$ Experimental evidence (e.g. Andreoni and Miller (2002) and Fehr and Schmidt (1999)) supports the idea of heterogeneous individuals with respect to altruistic preferences.

${ }^{18}$ As Pauly (1973) argues, altruism is motivated by perceiving the plight of others, and dire living conditions close-by are more likely to be perceived than those far away. As pointed out in section 2, altruism that is motivated by a preference for not being confronted with poverty and its manifestations is also likely to depend on the level of poverty in the vicinity of the taxpayer.
} 
will settle in the country with higher welfare transfers, while one with $\alpha_{k}<$ $\alpha^{*}$ chooses the country with lower transfer levels. ${ }^{19}$ Thus, the more altruistic taxpayers choose the country with higher taxation and higher welfare benefits.

Given the taxpayers' migration decision, the model is solvable by backward induction: Each country non-cooperatively and simultaneously chooses a tax level while taking into account the other country's possible decision and the resulting taxpayer migration. Taxpayers then choose whether to stay in their home country or migrate. The optimization problem for country $i$ 's tax revenues is thus

$$
\max _{b_{i}} b_{i} \times m_{i}\left(x, b_{i}, b_{j}, n_{i}, n_{j}\right)
$$

where $m_{i}$ is the number of taxpayers who settle in country $i$.

Several formulations of the altruistic preferences can now be imagined, based on the different concepts of altruism presented in the previous section. These are summarized in Table 2. As can be seen from these formulas, in the warm glow case utility from transfers only depends on the own contribution. In the pure altruism case, the size of the transfer to each individual poor person matters, while in the inequity aversion case, the sign of $W$ changes from + to - (as income differences create disutility) and disutility depends on the difference between disposable income and the transfer to each individual welfare recipient.

Given this setup, unique pure strategy NE values for taxation can be found which differ from the Race to the Bottom result of zero taxation. These equilibria will be derived in the following sections. The simple intuition for the existence of equilibria with positive taxation is that governments provide a good which is coveted by mobile taxpayers. The repelling effect of a lower disposable income is countered by the attraction of the good.

To illustrate the typical results of tax competition models lacking mobility constraints or other competition-reducing assumptions, I will briefly cover the results of the model in the absence of altruism. In this case, the utility of a taxpayer will only depend on his or her disposable income in a given country, that is, $U_{k, i}=V\left(x-b_{i}\right)$. Obviously, all taxpayers will choose to move to the country that levies the lowest tax rate as their preferred tax rate is zero.

The implication for the tax competition between two states is that a country

\footnotetext{
${ }^{19}$ Note that, depending on $b_{i}$ and $b_{j}, \alpha^{*}$ can take values greater than $l$ and smaller than 0 . But this only means that, given the distributional boundaries $\alpha$, there is no such taxpayer in the population. Therefore, if $\alpha^{*}$ is "out of bounds", all taxpayers have either $\alpha<\alpha^{*}$ and will move to the low benefit country, or $\alpha>\alpha^{*}$, resulting in a full relocation to the high benefit country.
} 
can attract all taxpayers by marginally undercutting the other's tax rate. This will lead to ever smaller tax rates as countries continuously undercut each other, resulting in the only stable outcome of zero taxation in both countries. Any country setting a positive tax rate will not have a tax base to charge taxes from. This is also the result in the Weichenrieder and Busch (2007) model in the case of perfectly mobile, non-altruistic taxpayers without "delayed integration" and in line with the standard non-collusive result of Bertrand competition.

\subsection{Introducing warm glow preferences}

In the warm glow setting, a taxpayer receives utility from his own tax payment, regardless of the resulting individual transfer to each welfare recipient. Taxpayer $k$ 's utility in country $i$ is now given by

$$
U_{k, i}=V\left(x-b_{i}\right)+\alpha_{k} b_{i}
$$

and the indifferent taxpayer's $\alpha^{*}$, from (2), is determined by

$$
\alpha^{*}=\frac{V\left(x-b_{j}\right)-V\left(x-b_{i}\right)}{b_{i}-b_{j}}
$$

The preferred tax rate of taxpayer $k, b_{k}$, is implicitly given as a function of the strength of his altruistic sentiment. It is derived by maximizing (4) with respect to $b_{i}$, denoting $\partial V\left(x-b_{i}\right) / \partial b_{i}$ as $V^{\prime}\left(x-b_{i}\right)$, and replacing $b_{i}$ by $b_{k}$ :

$$
V^{\prime}\left(x-b_{k}\right)=\alpha_{k}
$$

The number of taxpayers in countries $i$ and $j$ (denoted by $m_{i}$ and $m_{j}$ ) given $b_{i}$ and $b_{j}$ is determined by $\alpha^{*}$. Remember that the country setting the lower tax rate will attract all taxpayers with $\alpha<\alpha^{*}$ as utility from transfers is equal to tax payments in this setting. Given the distribution of $\alpha$ it is possible to calculate the number $m$ of taxpayers with $\alpha<\alpha^{*}$ from the cumulative distribution function (cdf) of a truncated normal distribution:

$$
m=\frac{\Phi\left(\frac{\alpha^{*}-\mu}{\sigma}\right)-\Phi\left(\frac{0-\mu}{\sigma}\right)}{\Phi\left(\frac{l-\mu}{\sigma}\right)-\Phi\left(\frac{0-\mu}{\sigma}\right)}
$$

The term on the right-hand side gives the value of the cdf at $\alpha^{*}$, with $\Phi$ being the cdf of a standard normal distribution. See Figure 2 for a graphical example. As the mass of taxpayers is normalized to 1, (7) directly gives the number of 
taxpayers who choose the country with the lower tax rate. The number of people settling in the higher tax country is thus simply $1-m$.

Having determined the migration decision of the taxpayers, it is possible to calculate the tax revenues for each country. Tax revenue $\pi_{i}$ in country $i$ is given by

$$
\pi_{i}=b_{i} \times m_{i}= \begin{cases}b_{i} \times m & \text { if } b_{i}<b_{j} \\ b_{i} \times(1-m) & \text { if } b_{i}>b_{j} \\ 0.5 \times b_{i} & \text { if } b_{i}=b_{j}\end{cases}
$$

Taking the other country's taxation decision as given, country $i$ will decide on a tax revenue maximizing tax rate.

Now define $b^{*}$ as the tax rate preferred by the taxpayer whose $\alpha$ is equal to the median of the truncated normal distribution from which $\alpha$ is drawn. One half of the taxpayers will prefer a higher tax rate, one half a lower tax rate than the median taxpayer. The median of the truncated distribution, denoted as $\mu^{*}$, is calculated from the mean and standard deviation of the underlying normal distribution as follows:

$$
\mu^{*}=\Phi^{-1}\left(\frac{\frac{1}{2} \times\left(\Phi\left(\frac{l-\mu}{\sigma}\right)+\Phi\left(\frac{0-\mu}{\sigma}\right)\right)-\mu}{\sigma}\right)
$$

From (6), by substituting $\mu^{*}$ for $\alpha_{k}$ and $b^{*}$ for $b_{k}, b^{*}$ is implicitly given by

$$
V^{\prime}\left(x-b^{*}\right)=\mu^{*}
$$

The median taxpayer will only favour redistribution if (10) holds for nonnegative $b^{*}$, which becomes more likely as $x$ and, by the properties of $V, \mu^{*}$ increase. Similarly, the desired amount of redistribution increases in $x$ and $\mu^{*}$.

I will now show that $b^{*}$ (if non-negative) is the tax rate adopted by both countries in the unique pure strategy NE of this model. The analytical proofs for existence, stability and uniqueness can be found in the Appendix.

If both countries set their tax rates equal to $b^{*}$, each country will attract exactly half of the total population of mobile taxpayers. An unilateral deviation by a country cannot increase its tax revenues: If it sets a lower tax rate, it loses taxpayers and levies a lower per capita tax rate. If it sets a higher tax rate, the negative migratory response outweighs the beneficial effect of having higher per capita tax revenues.

If one country does not set a tax rate of $b^{*}$, the other country reacts in 
the following way: Assume that country $j$ deviates from $b^{*}$. If it sets a lower tax rate, country $i$ can set a higher tax rate than country $j$ and attract more taxpayers as more than half the number of taxpayers prefers a tax rate higher than the one set by $j$. If country $j$ sets a higher tax rate than $b^{*}$, country $i$ can marginally undercut this tax rate and attract more taxpayers at a higher tax rate than $b^{*}$. Country $i$ 's best-response function thus takes the form

$$
b_{i}= \begin{cases}b_{j}-\varepsilon & \text { if } b_{j}>b^{*} \\ \frac{1-m}{\partial m / \partial b_{i}}>b_{j} & \text { if } b_{j}<b^{*} \\ b^{*} & \text { if } b_{j}=b^{*}\end{cases}
$$

An exemplary best-response function is shown in Figure 3. If $b^{*}>0$, a pure strategy NE exists. ${ }^{20}$

The NE tax rate implicitly given by (10) displays several characteristics: First, a full Race to the Bottom is avoided as both countries will choose the same positive tax rate if (10) holds for non-negative $b^{*}$, which becomes more probable as $\mu, l$ and $x$ increase (from (9), $\mu^{*}$ is a positive function of $\mu$ and l). Second, an increase in the mean value and the upper limit of the altruistic preferences distribution will increase the optimal tax rate as can be seen from (10) and (9), while the effect of an increase in $\sigma$ depends on whether $\mu$ is above (negative effect) or below (positive effect) $l / 2$. The reason for this mechanism is that if $\alpha$ were uniformly distributed between 0 and $l$, the optimal tax rate would be the one preferred by the taxpayer with $\alpha=l / 2$. As the standard deviation of the normal distribution increases, it becomes closer in form to the uniform distribution, and therefore the equilibrium tax rate with a normal distribution will converge towards the one achieved with a uniform distribution. Third, due to the quasi-linear formulation of preferences, with a sufficiently large $x$ all further increases in income will be taxed away to provide welfare transfers. Welfare recipients can thus end up with a higher income than taxpayers. This feature of

\footnotetext{
${ }^{20}$ As long as (6) holds for non-negative $b_{i}$ if $\alpha=l$, zero taxation is still not a possible outcome of tax competition as at least taxpayers with an $\alpha$ of $l$ will still be in favour of some taxation. The marginal utility from welfare benefits is $l$ for an individual with $\alpha=l$, so he or she prefers taxation if the marginal utility from disposable income is smaller than $l$, which in the quasi-linear setting is the case if $-V^{\prime}(x-b)<l$. A country will be able to attract the most altruistic taxpayers and generate tax revenues by setting a tax rate between 0 and the tax rate which makes the most altruistic taxpayer just indifferent between no taxation and taxation with redistribution. However, this will only be a NE in mixed strategies as a country slightly undercutting the other's tax rate will be able to attract all taxpayers who would prefer a zero-level of taxation. But playing a mixed strategy with a positive probability of setting a non-zero tax rate dominates constantly choosing a tax rate of 0 .
} 
the model stems only from the quasi-linear formulation and has no implications for the real world, of course. By appropriately choosing the parameters of the model, it would be possible to rule out this result.

Proposition 1: Assuming warm glow preferences, if $b^{*}>0$ a unique and stable pure strategy NE for taxation exists in which both countries choose the non-zero tax rate that corresponds to the one preferred by the taxpayer with $\alpha=\mu^{*}$.

Proof: See the Appendix.

This result is not affected in any way by the number of welfare recipients as taxpayers value only the size of their own contribution, not the impact it has on individual welfare payments.

In the case of warm glow altruism, the NE is robust to the relaxation of the assumption that countries choose their tax rates simultaneously. Assume that country $i$ moves first. As shown in the Appendix, the best tax rate country $i$ can set is $b^{*}$. If country $i$ chooses a lower tax rate, country $j$ will be able to attract more taxpayers than country $i$ at a higher tax rate at the expense of country $i$. Country $i$ will end up with less taxpayers and a lower tax rate if it sets $b_{i}<b^{*}$ which is clearly not optimal. If country $i$ chooses a higher tax rate than $b^{*}$, country $j$ will find it optimal to set a marginally lower tax rate which will lead to migration towards country $j$. In the case of $b_{i}>b_{j}>b^{*}$, the negative migratory effect offsets country $i$ 's gains from a higher tax rate, and thus setting a higher tax than $b^{*}$ cannot be optimal. Therefore, as country $j$ will never choose $b_{j}=b_{i} \neq b^{*}$ because it can do better by setting a higher or lower tax rate, and as country $i$ 's tax revenues will always be non-optimal if it sets $b_{i} \neq b^{*}$, the best option country $i$ has is to choose $b_{i}=b^{*}$ as this will induce country $j$ to also select this tax rate. The model thus confers neither a first-mover advantage nor disadvantage.

The results of the warm glow model are neither affected by asymmetry between the two countries with respect to the number of welfare recipients nor by spatial altruistic preferences (concern for the poor in other jurisdictions) as in Pauly (1973). $n_{i}$ and $n_{j}$ do not enter the utility function of taxpayers, and a taxpayer's own contribution generates utility regardless of the resulting individual transfer to each welfare recipient and his location. 


\section{Introducing pure altruism and inequity aver- sion preferences}

\subsection{Symmetric countries}

In this section I introduce pure altruism and inequity aversion as two other possible ways to model other-regarding preferences. I first consider the symmetric case, $n_{i}=n_{j}$. It turns out that in this case pure altruism and inequity aversion only support unstable pure strategy NE.

With pure altruism preferences, transfers made by all taxpayers within a country enter the utility function of each taxpayer, and so does the number of welfare recipients. Hence, taxpayer $k$ 's utility in country $i$ is now given by

$$
U_{k, i}=V\left(x-b_{i}\right)+\alpha_{k} \times \frac{b_{i} m_{i}}{n_{i}}
$$

Note that utility now not only depends on the tax rate, but also on the number of poor and the number of taxpayers within the chosen country. Assuming pure altruism preferences and given a sufficiently large $\mu^{*}$ and $x$, an unstable unique pure strategy NE for taxation exists in which both countries choose the non-zero tax rate that is preferred by the taxpayer with median altruistic preferences (see Appendix for a proof). The equilibrium tax rate is decreasing in the number of poor. The instability stems from the fact that the migratory response induced by a tax rate change will trigger another migratory movement away from the deviating country. An outflow of taxpayers makes the deviating country less attractive for taxpayers, and emigration continues until all taxpayers are concentrated in the other country.

Under the assumption of altruism motivated by inequity aversion, taxpayers care about the difference between their disposable income and the income (consisting solely of the transfer) of each individual welfare recipient. The transfer income in turn depends on the number of taxpayer living within a given country. The main difference to pure altruism is that, as can be seen in (13), the tax

rate enters the utility function positively twice. Inequity aversion thus presents a "stronger" kind of altruism than pure altruism. Taxpayer $k$ has a utility function of the form

$$
U_{k, i}=V\left(x-b_{i}\right)-\alpha_{k} \times\left(x-b_{i}-\frac{b_{i} m_{i}}{n_{i}}\right)
$$


A unique pure strategy NE exists with inequity aversion preferences but it is also unstable because the same migratory responses will follow a deviation from the optimal tax rate as in the pure altruism case. A graphical comparison between the equilibrium tax rates achieved under each preference assumption is shown in Figure 4.

\subsection{Asymmetric countries}

A more interesting case is the outcome of tax competition with asymmetric countries with respect to the number of welfare recipients. One could expect that countries which have to support a smaller number of poor people have an advantage in the competition for taxpayers, at least if the transfer per welfare recipient matters as in the inequity aversion and pure altruism cases. Taxation under the assumption of a warm glow feeling from paying taxes is not affected, as a taxpayer's utility depends neither on the number of other taxpayers in his jurisdiction, nor on the income of the poor. A smaller number of poor indicates a richer country as the distribution of taxpayers is assumed to be even at the outset. $^{21}$

Intuitively, introducing asymmetry prevents the poorer country from mimicking the richer country's taxation choices, while the richer country has no incentive to marginally undercut or exceed the poorer country's tax rate. Migratory movements are no longer all-or-nothing as in the symmetric case because tax rates have to be different for rich and poor countries in equilibrium. With sufficiently altruistic taxpayers, asymmetric countries allow for a stable NE in contrast to the symmetric case. ${ }^{22}$

An equilibrium in the case of asymmetric countries has to fulfill two conditions: First, no taxpayer must have an incentive to migrate given his altruistic preferences, the distribution of taxpayers and the tax rates. Second, no country must have an incentive to alter its tax rate and thereby generate higher tax revenues. It is obvious that in any equilibrium the country with the larger number of poor will set a lower tax rate than the other one as it has a disadvantage in welfare provision: For a given tax rate, the individual transfer decreases in the

\footnotetext{
${ }^{21}$ This is not synonymous with a smaller country size. It has been argued, for instance by Chatelais and Peyrat (2008), that small countries are drivers of tax competition as their benefits (attracting taxpayers) from lowering the tax rate outweigh the drawbacks (lower tax rates) in relation to their small GDP. This is not the case for large countries.

${ }^{22}$ The assumption that taxpayers differ in their valuation of redistribution is crucial here. If all taxpayers were the same obviously either no or every taxpayer would migrate in reaction to a change in tax rates.
} 
number of poor people. If a poor and a rich country were to set the same tax rate all taxpayers would locate in the rich country as they could then benefit from higher welfare provision at the same tax rate. Thus, the rich country could attract all taxpayers by imitating the poor country's tax rate if it were higher than its own in the first place. The rich country will also be able to provide higher welfare benefits than the poor one which means that $m_{i}=1-m$ in equilibrium, so the less altruistic taxpayers will settle in the poor country.

Taking the poor country's taxation decision as given, the rich country faces an outflow of taxpayers when increasing its tax rate which will here be illustrated for the case of pure altruism (inequity aversion is analytically similar). Assume that $n_{i}<n_{j}$, i.e. that country $i$ is rich and decides on setting a tax rate $b_{i}>b_{j}$. Country $i$ 's tax revenue function is then given by

$$
\pi_{i}=b_{i} \times m_{i}=b_{i} \times\left(1-\frac{\Phi\left(\frac{\alpha^{*}-\mu}{\sigma}\right)-\Phi\left(\frac{0-\mu}{\sigma}\right)}{\Phi\left(\frac{l-\mu}{\sigma}\right)-\Phi\left(\frac{0-\mu}{\sigma}\right)}\right)
$$

$\pi_{i}$ is a function of $\alpha^{*}$ which, from (2), is given by

$$
\alpha^{*}=\frac{V\left(x-b_{j}\right)-V\left(x-b_{i}\right)}{\frac{b_{i} m_{i}}{n_{i}}-\frac{b_{j}\left(1-m_{i}\right)}{n_{j}}}
$$

The number of taxpayers in country $i$ falls with $b_{i}$ as the derivative of (15) with respect to $b_{i}$ is positive (remember that taxpayers with $\alpha<\alpha^{*}$ prefer to live in the country with lower welfare provision, i.e. the poor one):

$$
\frac{\partial \alpha^{*}}{\partial b_{i}}=\frac{V^{\prime}\left(x-b_{i}\right)}{\left(\frac{b_{i} m_{i}}{n_{i}}-\frac{b_{j}\left(1-m_{i}\right)}{n_{j}}\right)}+\frac{m_{i} \times\left(V\left(x-b_{i}\right)-V\left(x-b_{j}\right)\right)}{n_{i} \times\left(\frac{b_{i} m_{i}}{n_{i}}-\frac{b_{j}\left(1-m_{i}\right)}{n_{j}}\right)^{2}}>0
$$

So $m_{i}$ falls as $\alpha^{*}$ increases, which in turn will again increase $\alpha^{*}$ :

$$
\frac{\partial \alpha^{*}}{\partial m_{i}}=-\frac{b_{i} \times\left(V\left(x-b_{j}\right)-V\left(x-b_{i}\right)\right)}{n_{i} \times\left(\frac{b_{i} m_{i}}{n_{i}}-\frac{b_{j}\left(1-m_{i}\right)}{n_{j}}\right)^{2}}<0
$$

But as the second derivative of (15) with respect to $m_{i}$ is positive and the second derivative of $m_{i}$ with respect to $\alpha^{*}$ is negative, the migratory response peters out (see Appendix). This means that a marginal change in tax rates will not induce all taxpayers to migrate to the same country. When choosing $b_{i}$, country $i$ thus can balance the positive effect of a higher tax rate against the negative effect of a smaller number of taxpayers. For a given $b_{i}$, the tax revenue function for country $j$ looks similar; $m_{j}$ is a decreasing function of $b_{j}$, and changes in $b_{j}$ 
will trigger only a limited migratory response.

$m_{j}=m$ (the number of taxpayers settling in the low welfare benefit country) as a function of $b_{i}$ is exemplarily shown in Figure 5. This function is convex in $b_{i}$, and thus $1-m$ is concave. If $\left.\pi_{i}\right|_{b_{j}}=b_{i} \times(1-m)$ has a global maximum in $b_{i}$ and $\left.\pi_{j}\right|_{b_{i}}=b_{j} \times m$ in $b_{j}$, a NE occurs if a combination of $b_{i}$ and $b_{j}$ exists for which both tax revenue functions are maximized. As shown in Figure 6, the existence of a NE depends on $\mu$ and $l$ : As both variables increase, and thus as the taxpayers become more altruistic, the existence of a NE becomes more likely. Furthermore, the resulting NE does not depend on the initial distribution of taxpayers, so it is stable because deviations from the equilibrium values of $b_{i}$ and $b_{j}$ will not lead to an endless cycle of tax adjustments as in the case of symmetric countries. Since explicitly solving the model if the number of poor differs between countries is impossible due to polynomial equations of high degree, the proof in the Appendix gives fairly general conditions for the existence and stability of an equilibrium.

The model results for varying $n_{j}$ given $n_{i}$ are shown in Figure 7. Starting from an initially given distribution of taxpayers, the values were achieved by letting the countries alternately choose their optimal (tax revenue maximizing) tax rate while taking into account the migratory responses. Using this mechanism, a NE is reached if no country has an incentive to deviate from its tax rate and the distribution of taxpayers between countries remains stable.

Tax rates generally increase in $\mu$, and inequity aversion, the stronger form of altruism, produces higher equilibrium outcomes. Increasing $n_{j}$ will raise the equilibrium tax rate in both countries. For the poorer country, this is because higher taxation is required and accepted by the remaining taxpayers to compensate for the reduced p.c. transfer, while for the richer country the relative advantage in welfare provision p.c. increases which makes a higher tax rate feasible. It is also important to note that most taxpayer locate in the high tax/low poverty country and the number of taxpayers is falling in $n_{j}$, so having to support only few welfare recipients in comparison to other countries confers a twofold advantage: On the one hand, higher tax rates are sustainable in equilibrium, and on the other hand, most tax payers prefer the high tax country.

Proposition 2: If countries differ with respect to the number of welfare recipients and given sufficiently high $x$ and $\mu^{*}$, a unique stable $N E$ exists with pure altruism and inequity aversion preferences in which the country with the lower number of poor will set higher taxes and attract more taxpayers. 
Proof: See the Appendix.

In comparison to autarky, the richer country may be able to generate higher tax revenues if the tax revenue losses from a potentially lower tax rate are offset by the gains from a larger tax base. The poorer country suffers a reduction in tax revenues if taxpayers are mobile as it will lose taxpayers and end up with a lower tax rate as well.

\section{Conclusion}

Existing models of tax competition predict that in the absence of migration costs and other barriers to migration, countries will be forced to lower taxes and dismantle their welfare states. In contrast, the model presented in this paper can explain the "stickiness" of taxpayers and the absence of a full Race to the Bottom due to migratory pressures by assuming an altruistic motivation of taxpayers. Warm glow preferences in general and pure altruism and inequity aversion preferences with countries asymmetric with respect to the number of poor inhabitants turn out to be sufficient to support stable NE.

The result put forward in Proposition 1 is based on a utility function that is in accordance with the notion of warm glow. The existence of a positive welfare transfer depends only on the income and the distribution of altruistic preferences. If taxpayers are suitably characterized by this utility function, it is fair to say that the high incomes in Western countries and the degree of social cohesion and identification with the political system, which could be used as a proxy for the strength of altruistic preferences, are sufficient to maintain welfare states. $^{23}$ A dispersion of preferences is increasing tax rates in the likely case that a population is on average less altruistic than a uniform distribution would suggest. Heterogeneity of preferences is experimentally found by Andreoni and Miller (2002), who also state that three quarters of their test subjects display some form of altruistic behavior.

Pitting poor and rich countries against each other, Proposition 2 is congruent with real-world observations: Poor countries struggle to keep their taxpaying population and set lower taxes, while rich countries are attractive as they only have to distribute their tax revenues to a smaller number of welfare recipients.

\footnotetext{
${ }^{23}$ An economic model dealing with the state-directed strengthening of these factors is put forward by Konrad (2008). In his model, countries can invest in the loyalty of their taxpayers which alters the outcome of tax competition between countries.
} 
E.g., the tax wedge was $60.5 \%$ in Belgium in 2009 for high-earning singles, but only $20.8 \%$ in Mexico and $34.9 \%$ in Poland (OECD, 2010). Even between wealthy countries, this effect should be visible, which could explain some of the pull high tax/low poverty countries such as Sweden with a positive net migration of about 60,000 in 2009 and Belgium exert on European migrants (Statistics Sweden, 2010).

Having stated the implications of the propositions, one should be aware that the model is mainly applicable to economically equally developed countries with politically and culturally similar inhabitants. The distribution of altruistic preferences certainly varies between Western countries, and even more so between the West and Eastern and Asian countries. ${ }^{24}$ The altruistic mobile tax base should be seen, also due to migration costs which are more important for migrants from other cultures and continents, in a European or at least Western context. Tax adjustments are long-term processes, so under the assumption of warm glow altruism and asymmetric pure altruism and inequity aversion one should not expect to see the predicted results at this time in European policy, but rather adjustments towards equilibrium.

Of course, migration decisions and the scope of welfare states do not depend on tax differentials alone, and tax competition is not the only problem arising from the free movement of production factors. ${ }^{25}$ As various studies suggest, countries can attract migratory flows through a host of other positive characteristics, and the generosity of welfare states is also dependent on political and economic factors. ${ }^{26}$ But the reasonable assumption of altruistic preferences when it comes to paying taxes can help to explain why the specter of the Race to the Bottom of welfare states has so far failed to materialize.

\section{References}

Alesina, A. F. and P. Giuliano (2009), Preferences for Redistribution, NBER Working Paper No. 14825.

Andreoni, J. (1990), Impure Altruism and Donations to Public Goods: A Theory of Warm-Glow Giving, The Economic Journal, Vol. 100, No. 401, pp. 464-477.

\footnotetext{
${ }^{24} \mathrm{~A}$ recent Eurobarometer poll shows that $53 \%$ of all respondents (EU citizens) hold national governments responsible for reducing poverty (European Commission, 2009). However, on a national level this figure varies greatly (24\% in France, $85 \%$ in Bulgaria).

${ }^{25}$ For instance, Holzner et al. (2009) examine the issue of "brain drain" in Germany.

${ }^{26}$ See, for instance, van Dalen and Henkens (2007).
} 
Andreoni, J. and J. Miller (2002), Giving According to GARP: An Experimental Test of the Consistency of Preferences for Altruism, Econometrica, Vol. 70, No. 2, pp. $737-753$.

Bakija, J. and J. Slemrod (2004), Do the Rich Flee from High State Taxes? Evidence from Federal Estate Tax Returns, NBER Working Paper No. 10645.

Basinger, S. J. and M. Hallerberg (2004), Remodeling the Competition for Capital: How Domestic Politics Erases the Race to the Bottom, American Political Science Review, Vol. 98, No. 2, pp. 261-276.

Boadway, R., M. Marchand, P. Pestieau, and M. Del Mar Racionero (2002), Optimal Redistribution with Heterogenous Preferences for Leisure, Journal of Public Economic Theory, Vol. 4, No. 4, pp. 475-498.

Bolton, G. E. and A. Ockenfels (2000), ERC: A Theory of Equity, Reciprocity, and Competition, The American Economic Review, Vol. 90, No. 1, pp. 166193.

Brueckner, J. K. (2000), Welfare Reform and the Race to the Bottom: Theory and Evidence, Southern Economic Journal, Vol. 66, No. 3, pp. 505-525.

Chatelais, N. and M. Peyrat (2008), Are small countries leaders of the European tax competition?, CES Working Paper 2008.58.

Crane, R. (1992), Voluntary income redistribution with migration, Journal of Urban Economics, Vol. 31, No. 1, pp. 84-98.

Cremer, H. and P. Pestieau (1998), Social insurance, majority voting and labor mobility, Journal of Public Economics, Vol. 68, No. 3, pp. 397-420.

- (2004), Factor mobility and redistribution, in Handbook of Regional and Urban Economics, Vol. 4, Amsterdam: North Holland, pp. 2529-2560.

Crumpler, H. and P. J. Grossman (2008), An experimental test of warm glow giving, Journal of Public Economics, Vol. 92, No. 5-6, pp. 1011-1021.

Cummings, R. G., J. Martinez-Vazquez, M. McKee, and B. Torgler (2009), Tax morale affects tax compliance: Evidence from surveys and an artefactual field experiment, Journal of Economic Behavior \& Organization, Vol. 70, No. 3. 
Dahlberg, M. and K. Edmark (2008), Is there a "race-to-the-bottom" in the setting of welfare benefit levels? Evidence from a policy intervention, Journal of Public Economics, Vol. 92, No. 5-6, pp. 1193-1209.

van Dalen, H. P. and K. Henkens (2007), Longing for the Good Life: Understanding Emigration from a High-Income Country, Population and Development Review, Vol. 33, No. 1, pp. 37-66.

Dixit, A., G. M. Grossman, and E. Helpman (1997), Common Agency and Coordination: General Theory and Application to Government Policy Making, Journal of Political Economy, Vol. 105, No. 4, pp. 752-769.

Doerrenberg, P., D. Duncan, C. Fuest, and A. Peichl (2012), Nice guys finish last: are people with higher tax morale taxed more heavily?, CGS Working Paper, Vol. 3, No. 2.

Egger, P. and D. M. Radulescu (2009), The Influence of Labour Taxes on the Migration of Skilled Workers, World Economy, Vol. 32, No. 9, pp. 1365-1379.

Ette, A. and L. Sauer (2010), Abschied vom Einwanderungsland Deutschland?, Policy paper for the Bertelsmann Foundation.

European Commission (2009), Eurobarometer-Studie zu Armut und sozialer Ausgrenzung, http://www.2010againstpoverty.eu.

Fehr, E. and K. M. Schmidt (1999), A Theory of Fairness, Competition, and Cooperation, The Quarterly Journal of Economics, Vol. 114, No. 3, pp. 817868.

Fichte, J. G. (no year), http://www.bk-luebeck.eu/zitate-fichte.html.

Gilardi, F. and F. Wasserfallen (2010), Tax policy diffusion: how much competition?, Paper for presentation at the Annual Meeting of the Swiss Political Science Association, Geneva.

Hamburger Abendblatt (2010), Milliardär Hopp fordert höheren Spitzensteuersatz, www.abendblatt.de.

Holzner, C., S. Munz, and S. Übelmesser (2009), Fiskalische Wirkungen der Auswanderung ausgewählter Berufsgruppen, Study for the Sachverständigenrat deutscher Stiftungen für Integration und Migration. 
Isaac, R. M. and J. M. Walker (1988), Group Size Effects in Public Goods Provision: The Voluntary Contributions Mechanism, The Quarterly Journal of Economics, Vol. 103, No. 1, pp. 179-199.

Kant, I. (1785), Grundlegung zur Methaphysik der Sitten, http://books.google.de, pp. 56-57.

Kleven, H., C. Landais, and E. Saez (2010), Taxation and International Migration of Superstars: Evidence from the European Football Market, NBER Working Paper No. 16545.

Konrad, K. (2008), Mobile tax base as a global common, International Tax and Public Finance, Vol. 15, pp. 395-414.

Mansoorian, A. and G. M. Myers (1993), Attachment to home and efficient purchases of population in a fiscal externality economy, Journal of Public Economics, Vol. 52, No. 1, pp. 117-132.

Meltzer, A. H. and S. F. Richard (1981), A Rational Theory of the Size of Government, Journal of Political Economy, Vol. 89, No. 5, pp. 914-927.

Ney, P. (2006), Charity as the Perfection of Natural Friendship in Aquinas' Summa Theologiae, Lethbridge Undergraduate Research Journal, Vol. 1, No. 1.

OECD (2007), Social Expenditure Database, http://www.oecd.org.

— (2010), Taxing Wages, http://www.oecd.org.

- (2011), Harmonized Unemployment Rates and Levels, http://www.oecd.org.

Orr, L. L. (1976), Income Transfers as a Public Good: An Application to AFDC, The American Economic Review, Vol. 66, No. 3, pp. 359-371.

Palfrey, T. R. and J. E. Prisbrey (1997), Anomalous Behavior in Public Goods Experiments: How Much and Why?, The American Economic Review, Vol. 87, No. 5, pp. 829-846.

Pauly, M. V. (1973), Income redistribution as a local public good, Journal of Public Economics, Vol. 2, No. 1, pp. 35-58. 
Razin, A., E. Sadka, and P. Swagel (2002), Tax burden and migration: a political economy theory and evidence, Journal of Public Economics, Vol. 85, No. 2, pp. $167-190$.

Schlicht, E. (1998), On Custom in the Economy, Oxford: Oxford University Press.

Sinn, H.-W. (1996), Social insurance, incentives and risk taking, International Tax and Public Finance, Vol. 3, pp. 259-280.

_ (2003), The New Systems Competition, Berlin: Blackwell Publishing.

Statistics Norway (2009), Population Statistics. Immigration and Emigration, http://www.ssb.no.

Statistics Sweden (2010), Population and Population Changes 1749-2009, http://www.scb.se.

Thompson, J. P. (2009), Costly Migration and the Incidence of State and Local Taxes, PERI Working Paper No. 251.

Tiebout, C. M. (1956), A Pure Theory of Local Expenditures, Journal of Political Economy, Vol. 64, No. 5, pp. 416-424.

Volden, C. (2002), The Politics of Competitive Federalism: A Race to the Bottom in Welfare Benefits?, American Journal of Political Science, Vol. 46, No. 2, pp. 352-363.

Weichenrieder, A. J. and O. Busch (2007), Delayed integration as a possible remedy for the race to the bottom, Journal of Urban Economics, Vol. 61, No. 3 , pp. 565-575.

Wildasin, D. E. (1991), Income Redistribution in a Common Labor Market, The American Economic Review, Vol. 81, No. 4, pp. 757-774.

Wilson, J. D. (1999), Theories of Tax Competition, National Tax Journal, Vol. 52 , No. 2, pp. 269-304.

ZDFinfokanal (2010), Der Club der Millionäre, http://infokanal.zdf.de. 


\section{Tables and Figures}

\begin{tabular}{|c|c|c|c|c|c|}
\hline Country & $\begin{array}{c}\text { AVERAGE } \\
\text { NET INCOME } \\
\text { FOR A } \\
\text { SINGLE } \\
\text { WORKER, } \\
\text { NO KIDS, } \\
\text { EARNING } \\
\text { 170\% OF } \\
\text { THE } \\
\text { AVERAGE } \\
\text { WAGE IN } \\
\text { US } \$(2005- \\
2009)\end{array}$ & $\begin{array}{c}\text { TAX WEDGE } \\
\text { FOR A } \\
\text { SINGLE } \\
\text { WORKER,NO } \\
\text { KIDS, } \\
\text { EARNING } \\
167 \% \text { OF } \\
\text { THE } \\
\text { AVERAGE } \\
\text { WAGE IN \% } \\
\text { (2009) }\end{array}$ & $\begin{array}{c}\text { NET } \\
\text { PUB- } \\
\text { LICLY } \\
\text { MAN- } \\
\text { DATED } \\
\text { SOCIAL } \\
\text { EXPEN- } \\
\text { DITURE } \\
\text { IN \% OF } \\
\text { GDP } \\
\text { (2007) }\end{array}$ & $\begin{array}{c}\text { AVERAGE } \\
\text { INDI- } \\
\text { RECT } \\
\text { TAX } \\
\text { RATE IN } \\
\% \\
(2007)\end{array}$ & $\begin{array}{c}\text { AVERAGE } \\
\text { UNEM- } \\
\text { PLOY- } \\
\text { MENT } \\
\text { RATE IN } \\
\% \\
(2005- \\
2009)\end{array}$ \\
\hline Austria & 53742.82 & 50.1 & 24.8 & 16.4 & 4.58 \\
\hline Belgium & 45383.41 & 60.5 & 26.2 & 15.1 & 7.84 \\
\hline Denmark & 53360.46 & 48.6 & 23.9 & 26.0 & 4.40 \\
\hline Finland & 50644.36 & 48.2 & 22.6 & 19.9 & 7.50 \\
\hline France & 48382.80 & 53.1 & 29.9 & 14.4 & 8.84 \\
\hline Germany & 49352.55 & 53.0 & 27.2 & 14.2 & 9.10 \\
\hline Luxembourg & 67303.30 & 41.1 & 19.1 & 23.7 & 4.70 \\
\hline Mexico & $\mathrm{N} / \mathrm{A}$ & 20.8 & 9.0 & 6.0 & 4.08 \\
\hline Netherlands & 55525.10 & 41.8 & 20.4 & 23.5 & 4.00 \\
\hline Norway & 74285.78 & 43.0 & 20.0 & 23.5 & 3.20 \\
\hline Poland & 12867.62 & 34.9 & 18.8 & 17.9 & 11.34 \\
\hline Spain & 38092.14 & 41.6 & 21.6 & 12.5 & 11.08 \\
\hline Sweden & 49578.42 & 50.9 & 26.0 & 20.7 & 7.08 \\
\hline Switzerland & 77866.91 & 33.6 & $\mathrm{~N} / \mathrm{A}$ & $\mathrm{N} / \mathrm{A}$ & 3.74 \\
\hline $\begin{array}{c}\text { United } \\
\text { Kingdom }\end{array}$ & 69274.85 & 37.0 & 22.7 & 12.8 & 5.74 \\
\hline $\begin{array}{l}\text { United } \\
\text { States }\end{array}$ & 47441.14 & 34.6 & 18.9 & 4.1 & 5.88 \\
\hline $\begin{array}{c}\text { OECD } \\
\text { Average }\end{array}$ & $\mathrm{N} / \mathrm{A}$ & 41.1 & 20.2 & 15.1 & 6.64 \\
\hline
\end{tabular}

Table 1: Tax wedges and welfare expenditures for selected OECD countries. (OECD, 2007,2010,2011) 


\begin{tabular}{|c|c|}
\hline TYPE OF ALTRUISTIC PREFERENCE & FORMAL REPRESENTATION \\
\hline No Altruism & $W \equiv 0$ \\
\hline Warm Glow & $W_{i}\left(b_{i}\right)=b_{i}$ \\
\hline Pure Altruism & $W_{i}\left(b_{i}, m_{i}, n_{i}\right)=b_{i} \times \frac{m_{i}}{n_{i}}$ \\
\hline Inequity Aversion & $W_{i}\left(x, b_{i}, m_{i}, n_{i}\right)=x-b_{i}-b_{i} \times \frac{m_{i}}{n_{i}}$ \\
\hline
\end{tabular}

Table 2: Formal representation of the different types of altruistic preferences

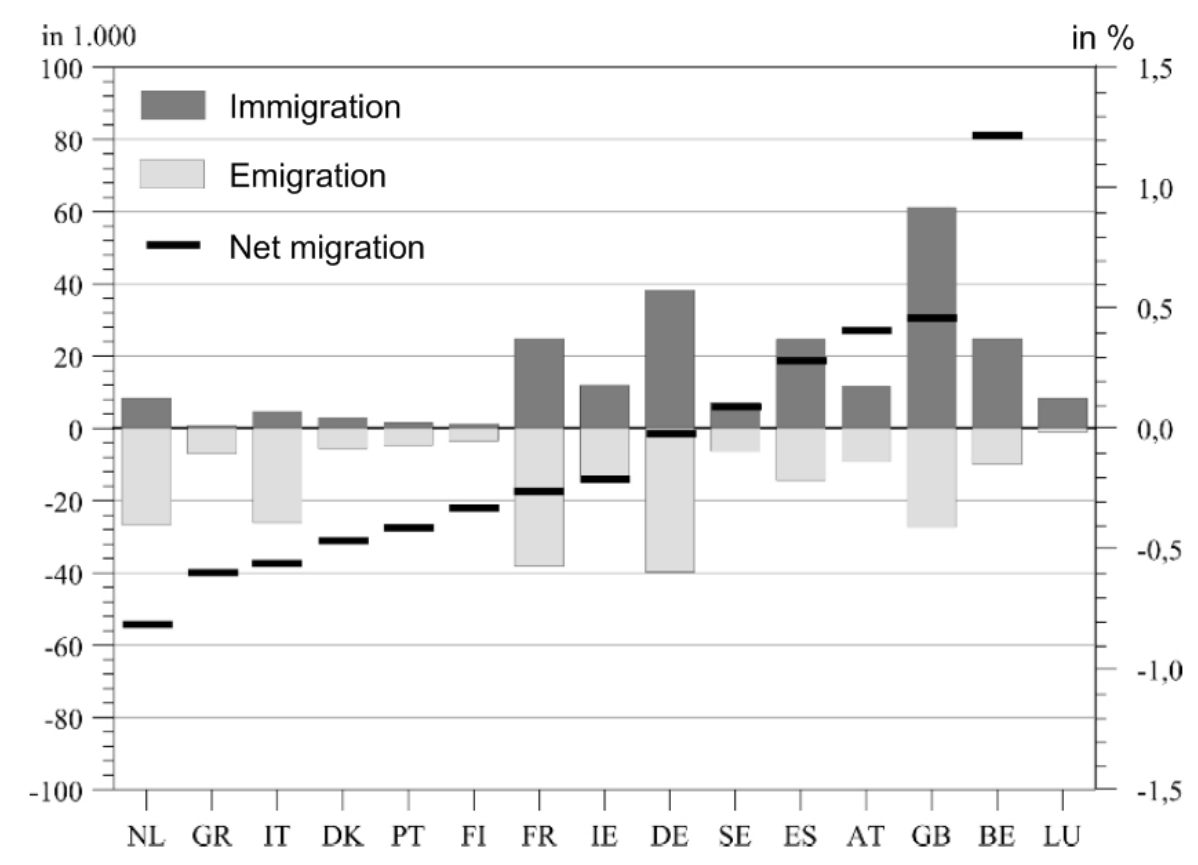

Figure 1: Emigration, immigration and net migration of "scientists" and "executives" (ISCO 1 and 2) between EU-15 countries, yearly averages between 2005 and 2009. Adapted from Ette and Sauer (2010) 


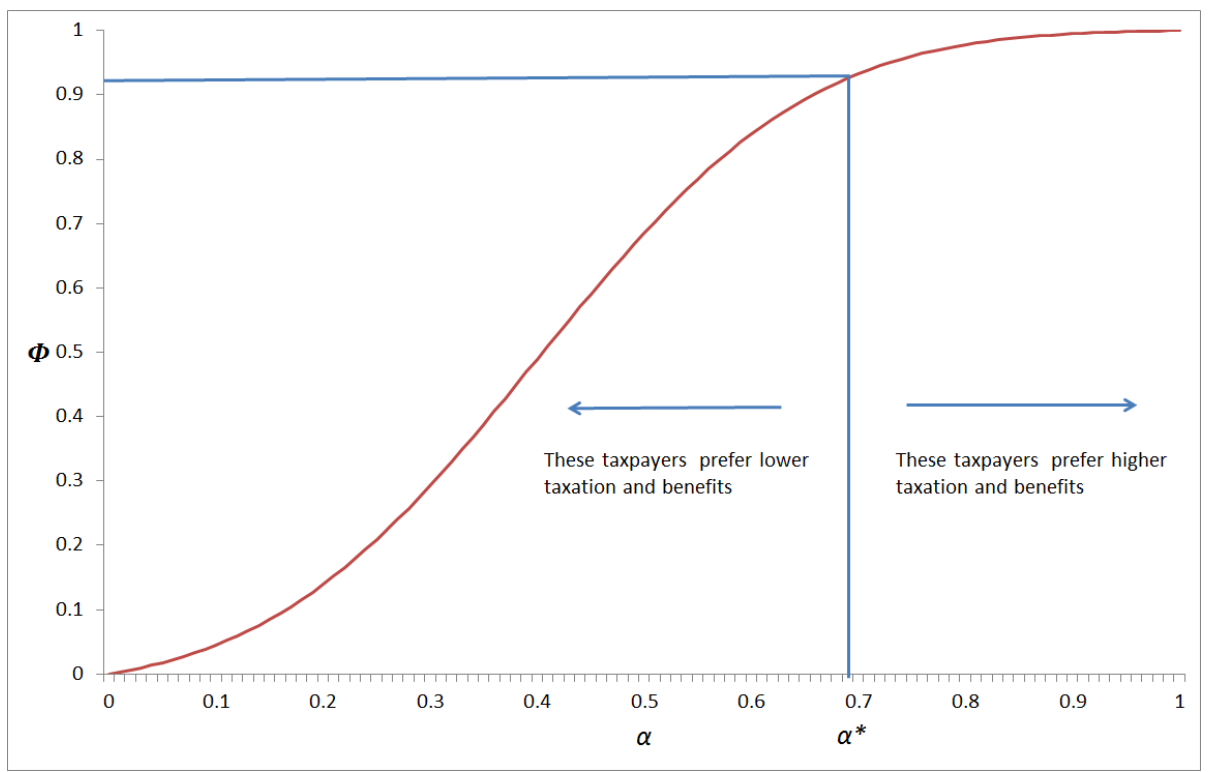

Figure 2: Cumulative distribution function of $\alpha$ with $\mu=0.4, \sigma=0.2, l=1$. 

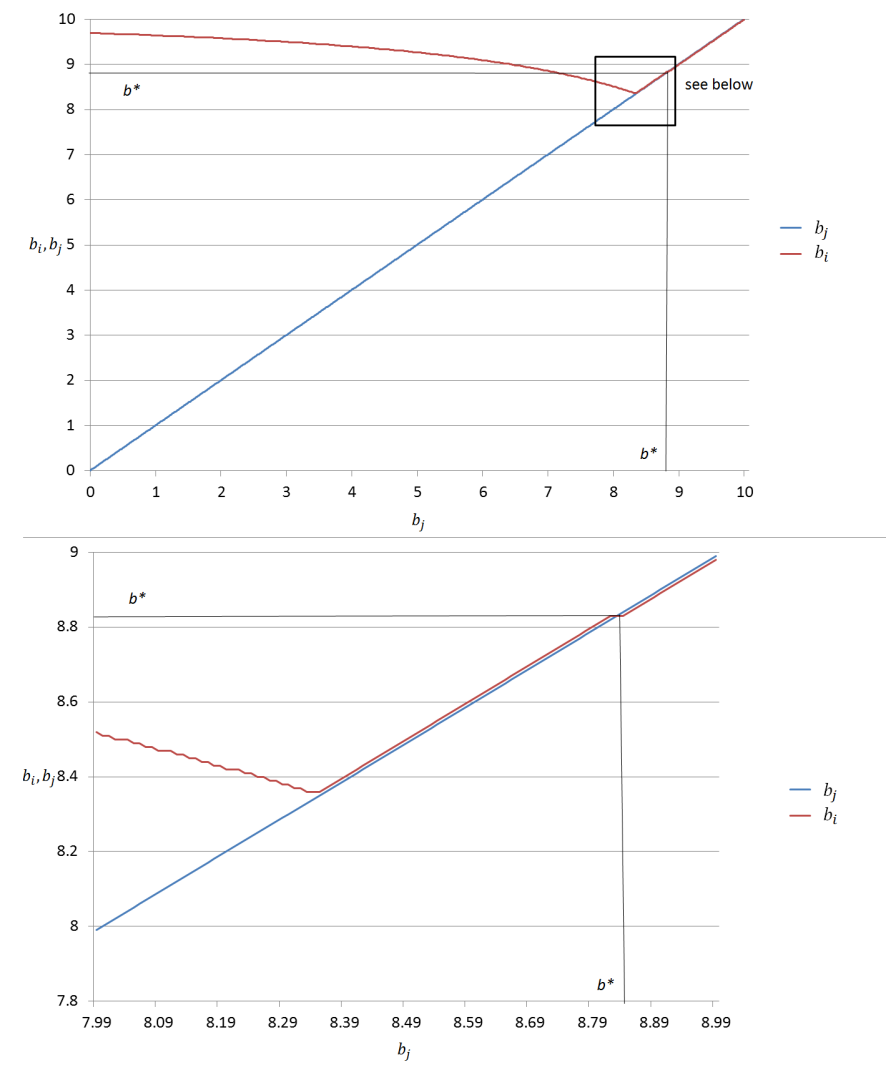

Figure 3: Best-response function of country $i$ to country $j$ 's tax rate with warm glow, $V(.) \equiv \sqrt{(.)}, x=10, \mu=0.4, \sigma=0.5, l=1$.
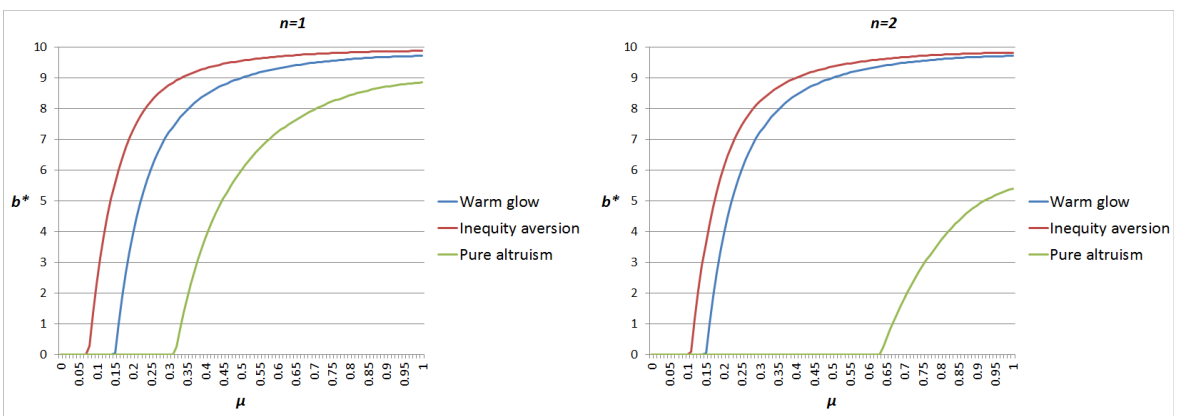

Figure 4: Equilibrium tax levels for symmetric pure altruism, inequity aversion and warm glow. $V(.) \equiv \sqrt{(.)}, x=10, \sigma=0.1, l=1$. 


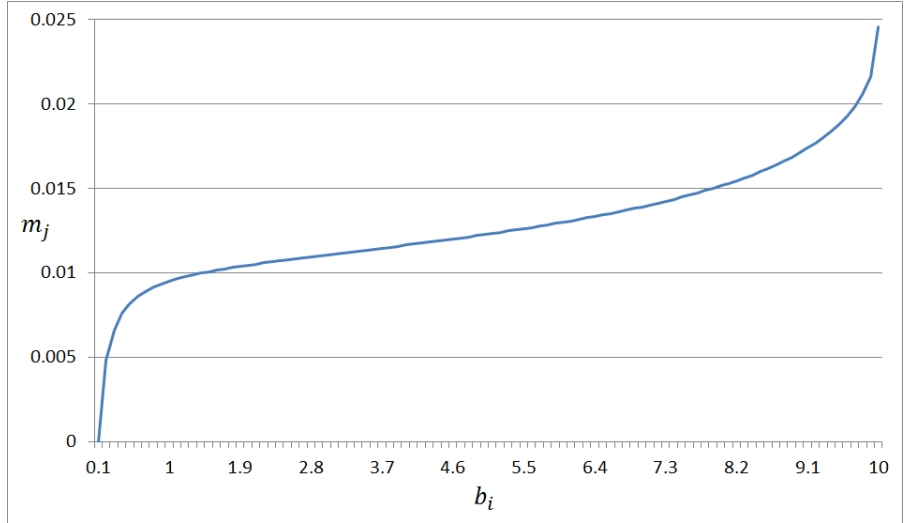

Figure 5: $m_{j}$ for varying $b_{i}$ with asymmetric pure altruism. $V(.) \equiv \sqrt{(.)}, x=$ $10, b_{j}=0.1, \mu=1, \sigma=1, l=3, n_{i}=1, n_{j}=2$.

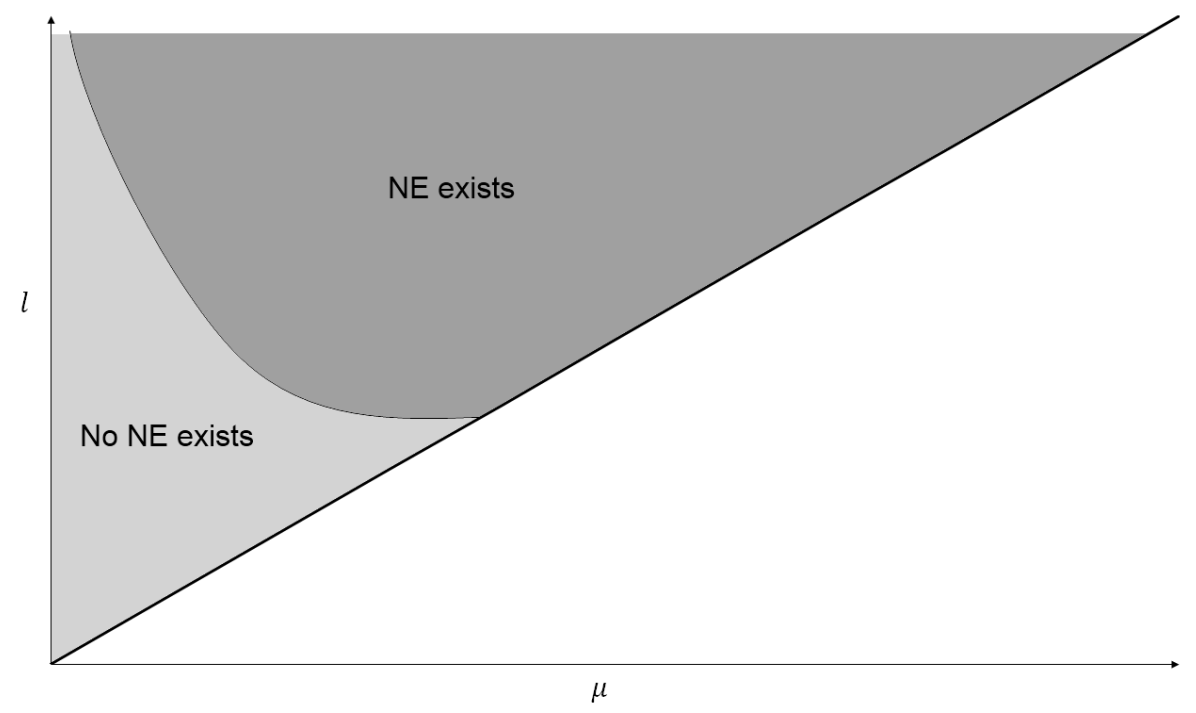

Figure 6: Existence of NE for pure altruism with asymmetric countries. 


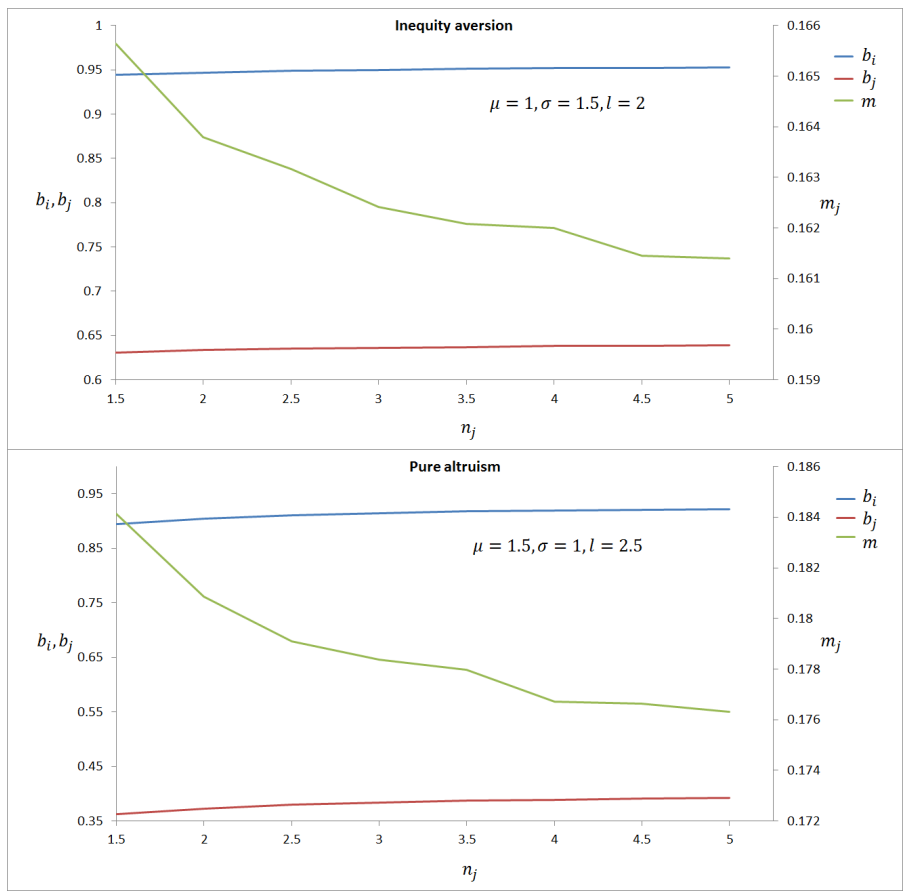

Figure 7: Equilibrium tax levels with asymmetric countries, $V()=.\sqrt{(.)}, x=$ $1, n_{i}=1$. 


\section{Appendix to section 3}

\section{Proof of the existence of a NE for warm glow}

There exists a symmetric NE in tax rates given by

$$
b_{i}=b_{j}=b^{*}
$$

Assume that country $j$ sets $b_{j}=b^{*}$. The number of taxpayers per country has to be 0.5 in a symmetric equilibrium, therefore it is necessary that $m_{i} \rightarrow 0.5$ as $b_{i} \rightarrow b^{*}$. Utilizing L'Hôpital's rule to determine the value of (5) as $b_{i} \rightarrow b^{*}$, the limit of $m_{i}$ is given by

$$
\lim _{b_{i} \rightarrow b^{*}} \frac{\Phi\left(\frac{\alpha^{*}-\mu}{\sigma}\right)-\Phi\left(\frac{0-\mu}{\sigma}\right)}{\Phi\left(\frac{1-\mu}{\sigma}\right)-\Phi\left(\frac{0-\mu}{\sigma}\right)}=\frac{\Phi\left(\frac{\mu^{*}-\mu}{\sigma}\right)-\Phi\left(\frac{0-\mu}{\sigma}\right)}{\Phi\left(\frac{l-\mu}{\sigma}\right)-\Phi\left(\frac{0-\mu}{\sigma}\right)}=0.5
$$

In equilibrium, $\pi_{i}=\pi_{j}$ and therefore it is required that $\pi_{i} \rightarrow \pi_{j}$ as $b_{i} \rightarrow b^{*}$ :

$$
\lim _{b_{i} \rightarrow b^{*}} \pi_{i}=\lim _{b_{i} \rightarrow b^{*}} b_{i} \frac{\Phi\left(\frac{\alpha^{*}-\mu}{\sigma}\right)-\Phi\left(\frac{0-\mu}{\sigma}\right)}{\Phi\left(\frac{l-\mu}{\sigma}\right)-\Phi\left(\frac{0-\mu}{\sigma}\right)}=\pi_{j}=\frac{b^{*}}{2}
$$

What is left to prove is that $\pi_{i}$ is strictly increasing (decreasing) in $b_{i}$ below (above) $b^{*}$. For $b_{i}<b^{*}$,

$$
\frac{\partial \pi_{i}}{\partial b_{i}}=b_{i} \times \frac{\frac{\partial \alpha^{*}}{\partial b_{i}} \times \frac{1}{\sigma} \phi\left(\frac{\alpha^{*}-\mu}{\sigma}\right)}{\Phi\left(\frac{l-\mu}{\sigma}\right)-\Phi\left(\frac{0-\mu}{\sigma}\right)}+\frac{\Phi\left(\frac{\alpha^{*}-\mu}{\sigma}\right)-\Phi\left(\frac{0-\mu}{\sigma}\right)}{\Phi\left(\frac{l-\mu}{\sigma}\right)-\Phi\left(\frac{0-\mu}{\sigma}\right)}>0
$$

with $\phi$ being the probability density function of a standard normal distribution. For $b_{i}>b^{*}$,

$$
\begin{gathered}
\frac{\partial \pi_{i}}{\partial b_{i}}=-b_{i} \times \frac{\frac{\partial \alpha^{*}}{\partial b_{i}} \times \frac{1}{\sigma} \phi\left(\frac{\alpha^{*}-\mu}{\sigma}\right)}{\Phi\left(\frac{l-\mu}{\sigma}\right)-\Phi\left(\frac{0-\mu}{\sigma}\right)}-\frac{\Phi\left(\frac{\alpha^{*}-\mu}{\sigma}\right)-\Phi\left(\frac{0-\mu}{\sigma}\right)}{\Phi\left(\frac{l-\mu}{\sigma}\right)-\Phi\left(\frac{0-\mu}{\sigma}\right)}+1<0 \\
i f b^{*}>\frac{\sigma\left(\Phi\left(\frac{l-\mu}{\sigma}\right)-\Phi\left(\frac{0-\mu}{\sigma}\right)\right)}{3 \times \phi\left(\frac{\mu^{*}-\mu}{\sigma}\right) \times V^{\prime \prime}\left(x-b^{*}\right)}
\end{gathered}
$$

The condition on $b^{*}$ ensures that the distribution of taxpayers is "dense" enough around the equilibrium tax rate so that the benefit from a higher tax rate is more than offset by a loss of taxpayers.

Hence, as $\pi_{i}$ strictly increases in $b_{i}$ if $b_{i}<b^{*}$ and strictly decreases in $b_{i}$ if 
$b_{i}>b^{*}$ and (A.5) holds, and as $\pi_{i}$ converges towards $0.5 \times b^{*}, b_{i}=b_{j}=b^{*}$ constitutes a NE.

\section{Proof of uniqueness of NE $b_{i}=b_{j}=b^{*}$ for warm glow}

Asymmetric NE, i.e. $b_{i} \neq b_{j}$, can be ruled out as a country having a lower tax level than the other can always increase its tax revenue by increasing its tax level:

$$
\frac{\partial \pi_{i}}{\partial b_{i}}=b_{i} \times \frac{\frac{\partial \alpha^{*}}{\partial b_{i}} \times \frac{1}{\sigma} \phi\left(\frac{\alpha^{*}-\mu}{\sigma}\right)}{\Phi\left(\frac{l-\mu}{\sigma}\right)-\Phi\left(\frac{0-\mu}{\sigma}\right)}+\frac{\Phi\left(\frac{\alpha^{*}-\mu}{\sigma}\right)-\Phi\left(\frac{0-\mu}{\sigma}\right)}{\Phi\left(\frac{l-\mu}{\sigma}\right)-\Phi\left(\frac{0-\mu}{\sigma}\right)}>0 \text { if } b_{i}<b_{j}
$$

Now assume that $b_{i}=b_{j}<b^{*}$. As $b^{*}$ is the tax level preferred by the taxpayer with mean altruistic preferences, one half of the voters prefers less and one half prefers more taxation and redistribution. It follows that less than half of the taxpayers prefers $b<b^{*}$. Thus, if country $i$ marginally increases its tax level, it can attract all taxpayers with a preferred $b$ larger than $b_{j}$ instead of just 0.5 taxpayers. Therefore,

$$
\frac{\partial \pi_{i}}{\partial b_{i}}>0, \text { if } b_{i}=b_{j}<b^{*}
$$

and there are no symmetric NE $b_{i}=b_{j}<b^{*}$.

Finally, consider the case of $b_{i}=b_{j}>b^{*}$. Country $i$ has an incentive to reduce its tax rate if there exists a $\pi_{i}$, given $b_{i}<b_{j}$, that is greater than $\frac{b_{j}}{2}$. This condition can be reformulated as

$$
\frac{\Phi\left(\frac{\alpha^{*}-\mu}{\sigma}\right)-\Phi\left(\frac{0-\mu}{\sigma}\right)}{\Phi\left(\frac{l-\mu}{\sigma}\right)-\Phi\left(\frac{0-\mu}{\sigma}\right)}>\frac{b_{j}}{2 b_{i}}
$$

As $b_{i} \rightarrow b_{j}$, this inequation becomes

$$
\frac{\Phi\left(\frac{V^{\prime}\left(x-b_{j}\right)-\mu}{\sigma}\right)-\Phi\left(\frac{0-\mu}{\sigma}\right)}{\Phi\left(\frac{l-\mu}{\sigma}\right)-\Phi\left(\frac{0-\mu}{\sigma}\right)}>\frac{1}{2}
$$

where the left-hand side gives the number of taxpayers settling in country $i$. Note that the left hand side converges towards a value greater than 0.5 because

$$
V^{\prime}\left(x-b_{j}\right)>V^{\prime}\left(x-b^{*}\right)
$$




$$
\Rightarrow \Phi\left(\frac{V^{\prime}\left(x-b_{i}\right)-\mu}{\sigma}\right)>\Phi\left(\frac{V^{\prime}\left(x-b^{*}\right)-\mu}{\sigma}\right)=0.5 \text { if } b_{j}>b^{*}
$$

This inequality always holds as the tax rate $b_{j}>b^{*}$ is preferred by less than half of the taxpayers, and thus the number of taxpayers attracted by $b_{j}-\varepsilon=b_{i}>b^{*}$ is greater than 0.5 . Therefore, country $i$ can always increase its tax revenues by deviating from $b_{i}=b_{j}>b^{*}$, and thus there are no symmetric NE with $b_{i}=b_{j}>b^{*}$.

\section{Proof of asymptotic stability of NE $b_{i}=b_{j}=b^{*}$ for warm glow}

Assume that $b_{j}<b_{i}=b^{*}$. Country $i$ may find it optimal to increase or decrease its tax level because $b_{i}=b^{*}$ may not fulfill the optimality criterion $\frac{\partial \pi_{i}}{\partial b_{i}}=0$ if $b_{j}<b_{i}=b^{*}$. If, on the one hand, country $i$ finds it optimal to set $b_{i}<b^{*}$ and attract more taxpayers at a lower tax level, then country $j$ will find it optimal, as outlined in the proof of uniqueness, to set a tax level of $b_{j}=b_{i}+\varepsilon$ and thus have a higher number of taxpayers at a higher tax rate. As now country $i$ will also set $b_{i}=b_{j}+\varepsilon$, this process continues and tax levels converge from below towards $b_{i}=b_{j}=b^{*}$.

If, on the other hand, country $i$ sets $b_{i}>b^{*}$ to increase its tax revenues by charging a higher tax from a lower number of taxpayers, country $j$ will also increase its tax level as $\frac{\partial \pi_{j}}{\partial b_{j}}>0$ if $b_{j}<b_{i}$. By setting $b_{j}=b_{i}-\varepsilon$, country $j$ will attract more taxpayers at a higher tax rate, which in turn will lead country $i$ to adjust its tax level to $b_{i}=b_{j}-\varepsilon$. This process continues and tax levels converge from above towards $b_{i}=b_{j}=b^{*}$.

\section{Appendix to section 4}

\section{Proof of the existence of a NE for pure altruism}

There exists a pure strategy NE given by

$$
b^{*}=b_{i}=b_{j}=x-\frac{n^{2}}{\left(\mu^{*}\right)^{2}}
$$


Assume that country $j$ chooses a tax level of $b^{*}$. Tax revenues in country $i$ are

$$
\pi_{i}=b_{i} \times m_{i}= \begin{cases}0.5 \times\left(x-\frac{n^{2}}{\left(\mu^{*}\right)^{2}}\right) & \text { if } b_{i}=b_{j}=b^{*} \\ b_{i} \times \frac{\Phi\left(\frac{\alpha^{*}-\mu}{\sigma}\right)-\Phi\left(\frac{0-\mu}{\sigma}\right)}{\Phi\left(\frac{l-\mu}{\sigma}\right)-\Phi\left(\frac{0-\mu}{\sigma}\right)} & \text { if } \frac{b_{i} m_{i}}{n_{i}}<\frac{b_{j}\left(1-m_{i}\right)}{n_{j}} \\ b_{i} \times\left(1-\frac{\Phi\left(\frac{\alpha^{*}-\mu}{\sigma}\right)-\Phi\left(\frac{0-\mu}{\sigma}\right)}{\Phi\left(\frac{l-\mu}{\sigma}\right)-\Phi\left(\frac{0-\mu}{\sigma}\right)}\right) & \text { if } \frac{b_{i} m_{i}}{n_{i}}>\frac{b_{j}\left(1-m_{i}\right)}{n_{j}}\end{cases}
$$

$\alpha^{*}$, however, is a function of $b_{i}$ with the first derivative

$$
\frac{\partial \alpha^{*}}{\partial b_{i}}=\frac{1}{2 \sqrt{x-b_{i}} \times\left(\frac{b_{i} m_{i}}{n}-\frac{b_{j}\left(1-m_{i}\right)}{n}\right)}+\frac{m_{i} \times\left(\sqrt{x-b_{i}}-\sqrt{x-b_{j}}\right)}{n \times\left(\frac{b_{i} m_{i}}{n}-\frac{b_{j}\left(1-m_{i}\right)}{n}\right)^{2}}>0
$$

Holding $m_{i}$ constant at 0.5 , any tax rate deviating from $b^{*}$ will be preferred by less than half of the taxpayers as $b^{*}$ is just the tax rate which half of the

taxpayers consider to be too low and half to be too high. This, in turn, further punishes a deviation from $b^{*}$ as

$$
\begin{aligned}
\frac{\partial \alpha^{*}}{\partial m_{i}} & =\frac{-\left(\frac{b_{i}}{n}+\frac{b_{j}}{n}\right) \times\left(\sqrt{x-b_{i}}-\sqrt{x-b_{j}}\right)}{\left(\frac{b_{i} m_{i}}{n}-\frac{b_{j}\left(1-m_{i}\right)}{n}\right)^{2}}<0 \text { if } b_{i}>b_{j} \\
\frac{\partial \alpha^{*}}{\partial m_{i}} & =\frac{\left(\frac{b_{i}}{n}+\frac{b_{j}}{n}\right) \times\left(\sqrt{x-b_{i}}-\sqrt{x-b_{j}}\right)}{\left(\frac{b_{i} m_{i}}{n}-\frac{b_{j}\left(1-m_{i}\right)}{n}\right)^{2}}>0 \text { if } b_{i}<b_{j}
\end{aligned}
$$

which means that a loss of taxpayers alters $\alpha^{*}$ unfavourably for country $i$. By positively deviating from $b^{*}$, country $i$ reduces its tax revenues as the outflow of taxpayers outweighs the higher tax rate per remaining taxpayer. A negative deviation can never be optimal as it attracts less taxpayers at a lower tax rate. Thus, $b^{*}$ is the optimal tax rate for country $i$ given $b_{j}=b^{*}$.

\section{Proof of the existence of a NE for inequity aversion}

The proof for the existence of a pure strategy NE with inequity aversion is similar to the pure altruism case and is available upon request.

\section{Proof of the existence and stability of a NE for asymmetric countries with pure altruism}

As has been discussed in section 4 , if $n_{i}<n_{j}$ an equilibrium can only exist with $b_{j}<b_{i}$. The tax revenue function of country $i$ is then given by 


$$
\pi_{i}=b_{i} \times m_{i}
$$

Define $P_{i}(z)$ as the first derivative of $\pi_{i}$ with respect to $b_{i}$ at $b_{i}=z$ :

$$
P_{i}\left(b_{i}\right) \equiv \frac{\partial \pi_{i}}{\partial b_{i}}=m_{i}+b_{i} \times \frac{\partial m_{i}}{\partial b_{i}}
$$

$m_{i}$ is a decreasing function of $b_{i}$,

$$
\frac{\partial m_{i}}{\partial b_{i}}=-\frac{\partial \alpha^{*}}{\partial b_{i}} \times \frac{\frac{1}{\sigma} \phi\left(\frac{\alpha^{*}-\mu}{\sigma}\right)}{\Phi\left(\frac{l-\mu}{\sigma}\right)-\Phi\left(\frac{0-\mu}{\sigma}\right)}<0
$$

as $\partial \alpha^{*} / \partial b_{i}$ is positive,

$$
\frac{\partial \alpha^{*}}{\partial b_{i}}=\frac{V^{\prime}\left(x-b_{i}\right)}{\left(\frac{b_{i} m_{i}}{n_{i}}-\frac{b_{j}\left(1-m_{i}\right)}{n_{j}}\right)}+\frac{m_{i} \times\left(V\left(x-b_{i}\right)-V\left(x-b_{j}\right)\right)}{n_{i} \times\left(\frac{b_{i} m_{i}}{n_{i}}-\frac{b_{j}\left(1-m_{i}\right)}{n_{j}}\right)^{2}}>0
$$

$\pi_{i}$ is a continuous function on the interval $] b_{j}, x\left[, P_{i}(z)<0\right.$ as $z \rightarrow x$ and $P_{i}(z)>0$ as $z \rightarrow b_{j}$ if $\left.m_{i}\right|_{b_{i} \rightarrow b_{j}}>\left.\left(\left|b_{i} \times \frac{\partial m_{i}}{\partial b_{i}}\right|\right)\right|_{b_{i} \rightarrow b_{j}}$, so $\pi_{i}$ has a local maximum on the interval $] b_{j}, x\left[\right.$. Similarly, $\pi_{j}$ has a local maximum on the interval $] 0, b_{i}$ [ if $\left.m_{j}\right|_{b_{j} \rightarrow b_{i}}<\left.\left(\left|b_{j} \times \frac{\partial m_{j}}{\partial b_{j}}\right|\right)\right|_{b_{j} \rightarrow b_{i}}$. The conditions on $\left.m_{i}\right|_{b_{i} \rightarrow b_{j}}$ and $\left.m_{j}\right|_{b_{j} \rightarrow b_{i}}$ hold if $n_{j}$ is sufficiently larger than $n_{i}$ and $\mu$ and $l$ are sufficiently high.

Setting (A.17) equal to zero and solving for $b_{i}$ gives the best response function for country $i$ 's tax rate given country $j$ 's tax rate. Define

$$
Q_{i}=-\frac{m_{i}}{\frac{\partial m_{i}}{\partial b_{i}}}
$$

as this best response function. $\frac{\partial Q_{i}}{\partial b_{j}}>0$ as $b_{j} \rightarrow 0$ and $Q_{i}=b_{j}$ as $b_{j} \rightarrow x$, so $Q_{i}$ is increasing in $b_{j}$. Furthermore, $P_{j}(z)<0$ as $z \rightarrow b_{i}$ and $P_{j}(z)>0$ as $z \rightarrow 0$, so the optimal tax rate response of country $j$ has to lie between 0 and $b_{i}$. Thus, an equilibrium in tax rates is reached where the positive effect on $Q_{i}$ from an increasing $b_{j}$ balances with the negative effect on $P_{i}(z)$ from approaching $x$, and where $P_{j}(z)$ equals 0 given $b_{i}$.

Denote by $b_{i}^{*}$ and $b_{j}^{*}$ an equilibrium in tax rates as given by the previous paragraphs. The second derivative of $m_{i}$ with respect to $\alpha^{*}$ is positive while the second derivative of (15) with respect to $m_{i}$ is negative, and thus the migratory response to a change in tax rates peters out, i.e. a deviation from equilibrium 
does not cause an all-or-nothing migratory response:

$$
\begin{gathered}
\frac{\partial^{2} m_{i}}{\partial\left(\alpha^{*}\right)^{2}}>0 \text { if } \alpha^{*}<\mu \\
\frac{\partial^{2} \alpha^{*}}{\partial m_{i}^{2}}=2 \times \frac{\left(\frac{b_{i}}{n_{i}}+\frac{b_{j}}{n_{j}}\right)^{2} \times\left(\sqrt{x-b_{j}}-\sqrt{x-b_{i}}\right)}{\left(\frac{b_{i} m_{i}}{n_{i}}-\frac{b_{j}\left(1-m_{i}\right)}{n_{j}}\right)^{3}}>0
\end{gathered}
$$

Thus, $b_{i} \rightarrow b_{i}^{*}$ and $b_{j} \rightarrow b_{j}^{*}$ if one or both countries do not initially choose their equilibrium tax rate.

\section{Proof of the existence of a NE for asymmetric countries with inequity aversion}

The proof for the existence of a pure strategy NE with inequity aversion is similar to the pure altruism case and is available upon request. 